\title{
Competing Presynaptic and Postsynaptic Effects of Ethanol on Cerebellar Purkinje Neurons
}

\author{
Zhen Ming, Hugh E. Criswell, Guozhong Yu, and George R. Breese \\ Departments of Psychiatry, Anesthesiology, and Pharmacology, Center for Alcohol Studies, UNC \\ Neuroscience Center, University of North Carolina School of Medicine, Chapel Hill, North Carolina
}

\begin{abstract}
Background-Ethanol has actions on cerebellar Purkinje neurons that can result either in a net excitation or in inhibition of neuronal activity. The present study examines the interplay of presynaptic and postsynaptic mechanisms to determine the net effect of ethanol on the neuronal firing rate of cerebellar Purkinje neurons.
\end{abstract}

Methods-Whole-cell voltage-clamp recording of miniature inhibitory postsynaptic currents (mIPSCs) from Purkinje neurons in cerebellar slices was used to examine the effect of ethanol on presynapticsynaptic release of $\gamma$-aminobutyric acid (GABA) and glutamate. Extracellular recording was used to examine the net action of both presynaptic and postsynaptic effects of ethanol on the firing rate of Purkinje neurons.

Results-Under whole-cell voltage clamp, the frequency of bicuculline-sensitive miniature postsynaptic currents (mIPSCs) was increased dose-dependently by 25,50 , and $100 \mathrm{mM}$ ethanol without any change in amplitude or decay time. Despite this evidence of increased release of GABA by ethanol, application of $50 \mathrm{mM}$ ethanol caused an increase in firing in some neurons and a decrease in firing in others with a nonrandom distribution. When both glutamatergic and GABAergic influences were removed by simultaneous application of 6-cyano-7-nitroquinoxaline-2,3-dione and picrotoxin, respectively, ethanol caused only an increase in firing rate.

Conclusions-These data are consistent with a dual action of ethanol on cerebellar Purkinje neuron activity. Specifically, ethanol acts presynaptically to increase inhibition by release of GABA, while simultaneously acting postsynaptically to increase intrinsic excitatory drive.

\section{Keywords}

Ethanol; GABA; Glutamate; mIPSC; Presynaptic; Postsynaptic; Intrinsic Drive

\begin{abstract}
IN VIVO STUDIES in urethane-anesthetized rats have generally shown an inhibition of neural activity by either systemic (Givens and Breese, 1990a) or locally applied ethanol (Freund et al., 1993). However, when other anesthetics or no anesthetic were used, systemic administration of ethanol produced a mixed action on cerebellar Purkinje neurons, with an increased rate occurring in some neurons and a decreased rate occurring in others (Rogers et al., 1980). Similarly, both increases and decreases in rate have been observed in recordings from Purkinje neurons in culture (Franklin and Gruol, 1987; Urrutia and Gruol, 1992) and in the cerebellar slice (Bloom and Siggins, 1987; Siggins et al., 1987). These changes in rate are
\end{abstract}

\footnotetext{
Copyright $@ 2006$ by the Research Society on Alcoholism

Reprint requests: Hugh E. Criswell, PhD, Center for Alcohol Studies, UNC School of Medicine, Thurston-Bowles Building, CB-7178 Chapel Hill, NC 27599-7178; Fax: 919-966-5679; HEC@ med.unc.edu.
} 
often accompanied by a change in the pattern of firing of the Purkinje neurons (Bloom and Siggins, 1987; Franklin and Gruol, 1987; Siggins et al., 1987).

Ethanol acts on a number of neurotransmitter-gated and G-protein-coupled ion channels (Crews et al., 1996). Additionally, ethanol can either increase (Ariwodola and Weiner, 2004; Crowder et al., 2002; Roberto et al., 2003; Ziskind-Conhaim et al., 2003) or decrease (ZiskindConhaim et al., 2003) neurotransmitter release. Purkinje neurons receive both excitatory and inhibitory synaptic inputs (Satake et al., 2004) and have an intrinsic pacemaker activity (Edgerton and Reinhart, 2003). Therefore, the differing effects of ethanol on these factors may be responsible for the mixed action of ethanol on Purkinje neuronal firing.

Because the basis of such integration for the varied effects of ethanol on cerebellar Purkinje neuronal activity has not yet been investigated, the present study used both whole-cell voltageclamp and extracellular recording to examine the potential basis of the variable actions of ethanol on cerebellar Purkinje neuronal activity in a slice preparation. This work included assessment of ethanol action on $\gamma$-aminobutyric acid (GABA) release, on the involvement of glutamate input, and on the intrinsic firing of cerebellar Purkinje neurons.

\section{METHODS AND MATERIALS}

\section{Preparation of Cerebellar Slices}

Sprague-Dawley rats, 13 to 18 days old, were anesthetized with an intraperitoneal (i.p.) injection of 1.5 to $2 \mathrm{~g} / \mathrm{kg}$ urethane and decapitated. The brains were rapidly removed and placed in ice-cold artificial cerebrospinal fluid (ACSF) of the following composition (in $\mathrm{mM}$ ): $\mathrm{NaCl}$ $124, \mathrm{KCl} 3.25, \mathrm{KH}_{2} \mathrm{PO}_{4} 1.25, \mathrm{CaCl}_{2} 2, \mathrm{NaHCO}_{3} 20, \mathrm{MgSO}_{4} 2$, and glucose 10 . The cerebella were isolated and parasagittal slices, $250 \mu \mathrm{m}$ thick, were cut with a vibrating tissue slicer (Vibratome, series 1000). The slices were stored in a beaker containing ACSF gassed with $95 \% \mathrm{O}_{2} / 5 \% \mathrm{CO}_{2}$. The slices were equilibrated at least 1 hour at room temperature before starting experiments.

\section{Recording from Purkinje Cells in Cerebellar Slices}

In both extracellular and patch-clamp recordings, a slice was placed at the bottom of a chamber attached to the stage of a microscope (BX51Wl, Olympus, Tokyo, Japan). The slice was superfused with ACSF gassed with $95 \% \mathrm{O}_{2} / 5 \% \mathrm{CO}_{2}$ at a flow rate of $1.5 \mathrm{~mL} / \mathrm{min}$ at room temperature $\left(21-24{ }^{\circ} \mathrm{C}\right)$. The cells were visualized using infrared illumination under differential interference contrast optics with a water-immersion lens $(\times 40)$ and displayed on a monitor via a video camera. Purkinje neurons were easily identified by their large size (20-25 $\mu \mathrm{m})$ and location at the border between the granule cells and molecular layers. Recording electrodes were pulled from borosilicate glass (Drummond Scientific Company, Broomall, PA) and had a resistance of 2.5 to $3 \mathrm{M} \Omega$. In whole-cell patch-clamp recordings, recording electrodes were filled with internal solution of the following composition (in $\mathrm{mM}$ ): $\mathrm{KCl} 150$, HEPES 15, K-ATP 2, EGTA 5, phosphocreatine 15, and creatine phosphokinase $50 \mathrm{U} / \mathrm{mL}$ (pH 7.4, adjusted with $\mathrm{KOH}$ ). In some sets of experiments, $\mathrm{GABA}_{\mathrm{A}}$ and glutamate receptor blockers were included in the perfusion solution, as indicated in the text. Control (ACSF) and ethanolcontaining ASCF solutions in sealed syringes were delivered through Teflon tubing connected to a multibarrel perfusion pencil ( $250 \mu \mathrm{m}$ in diameter), which was positioned 150 to $250 \mu \mathrm{m}$ from the cells tested. The switch of perfusion solutions was achieved by opening or closing the valves electronically. This system (ValveLink 8, AutoMate Scientific, San Francisco, CA) allowed rapid application and washout of the drugs. Action potentials or currents were recorded using an Axopatch-1D patch-clamp amplifier, and 80\% series resistance compensation was achieved when miniature inhibitory postsynaptic currents (mIPSCs) were recorded. Data were collected with pClamp 9.0 (Axon Instruments, Union City, CA). 
mIPSC Recording-Whole-cell voltage-clamp recording was used to determine the effect of ethanol on mIPSCs of Purkinje cells. Ten micromolar 6-cyano-7-nitroquinoxaline-2,3-dione (CNQX, Sigma, St. Louis, MO) and $50 \mu \mathrm{M}_{\mathrm{D}}$-2-amino-5-phosphonopentanoic acid (AP-5, Sigma) were included in the perfusion solution to block iono-tropic glutamate receptors. Purkinje cells near the surface of the slice were chosen because these cells were rapidly exposed to the ethanol. The holding potential was $-70 \mathrm{mV}$. After the membrane of the cell was broken, a control solution containing $1 \mu \mathrm{M}$ tetrodotoxin (TTX, Sigma), $10 \mu \mathrm{M} \mathrm{CNQX}$, and $50 \mu \mathrm{M}$ AP-5 was applied to the cell. Approximately 4 minutes after sodium currents (evoked by depolarizing pulses) disappeared, mIPSCs became stable. Then, varying concentrations of ethanol $(0,12.5,25,50$, or $100 \mathrm{mM})$ were applied, followed by control solution (washout). Only1 ethanol concentration was applied to each cell. When drugs were changed, a minimum of 3 minutes was allowed for equilibration. The mIPSCs were then recorded for 50 seconds during precontrol and postcontrol perfusions and ethanol application. Percent changes in frequency, amplitude, and decay time of mIPSCs during the application of ethanol were calculated by comparing those with the mean values of precontrol and postcontrol.

Extracellular Recording-For extracellular recordings, electrodes were filled with an $\mathrm{Na}^{1}$-based perfusion solution (ACSF). Cells near the surface of the slice were chosen to facilitate the drugs reaching those cells. The recording pipette tip was positioned just above, or slightly touching, the cell body. Following acquisition of stable spontaneous action potentials, the control solution was perfused onto the cell tested with the perfusion pencil. After waiting approximately 5 minutes for stabilization of the firing rate, $50 \mathrm{mM}$ ethanol was applied, followed by control solution. Beginning at least 3 minutes after changing the perfused drugs, action potentials were recorded for 50 to 60 seconds Burst duration, burst rate, and withinburst interspike interval were defined as illustrated in Fig. 4C. Burst duration and burst rate were measured using Clamp Fit (Axon Instruments) by setting the cursor at the beginning and end of a burst. Interspike interval within bursts was determined automatically by the minianalysis program from Synaptosoft (version 5.6.4; Decatur, GA). Within-burst interspike interval was determined for each burst and averaged across bursts for each condition within a single neuron. Each data point is a mean of 50 to 60 seconds. Percent changes in firing rates, within-burst interspike intervals, burst rates, and burst durations of spontaneous action potentials during the application of ethanol were calculated by comparing each with the mean values of precontrol and postcontrol. Frequency is defined as the number of action potentials/ $\mathrm{s}$ averaged across an entire 50 to 60 seconds sample.

\section{Analysis}

The data recorded with extracellular and patch-clamp recordings were analyzed with either Clampfit or miniAnalysis (Synaptosoft). Numerical data are given as mean $\pm \mathrm{SE}$, and $n$ represents the number of cells tested. Whenever appropriate, Student's $t$-test, analysis of variance (ANOVA), Shapiro-Wilk's distribution test, and correlation were performed as indicated. Calculated $p$ values of less than 0.05 were accepted as evidence of a significant difference.

\section{RESULTS}

\section{Effects of Ethanol on GABAergic mIPSCs from Purkinje Cells}

Action potential-independent mIPSCs were recorded after application of $1 \mu \mathrm{m}$ TTX, which abolished action potential-dependent currents. GABAergic mIPSCs were isolated by including the glutamate receptor blockers CNQX and AP-5 in the perfusion solution. The $\mathrm{GABA}_{\mathrm{A}}$ receptor blocker bicuculline $(10 \mu \mathrm{M})$ completely blocked the mIPSCs, indicating that they were GABA-mediated (data not shown, $n=4$ ). 
The frequency, amplitude, and decay times of mIPSCs recorded from Purkinje cells before the application of ethanol were $1.25 \pm 0.15 \mathrm{~Hz}, 245 \pm 10 \mathrm{pA}$, and $24.5 \pm 0.8 \mathrm{~ms}$, respectively $(n=$ 42). Percent potentiation of the frequency of mIPSCs by various concentrations of ethanol ( 0 , $12.5,25,50$, and $100 \mathrm{mM}$ ) relative to control frequency is plotted in Fig. 1A. Ethanol increased the frequency of the currents (1-way ANOVA, $p<0.0001, n=9-12$ for individual concentrations) in a concentration-dependent manner. Post hoc tests demonstrated that the percent change in frequency in the presence of 25,50 , and $100 \mathrm{mM}$ ethanol was significantly different from controls (Tukey's HSD test, $p<0.05$ ). Representative traces of mIPSCs from a Purkinje neuron recorded in the presence and absence of $50 \mathrm{mM}$ ethanol shows that ethanol increased the spontaneous activity of the cell (Fig. 1B).

As shown in Table 1, neither the amplitude nor the decay time of the mIPSCs was affected by the varying concentrations of ethanol.

\section{Effect of Ethanol on Spontaneous Glutamatergic Currents in Purkinje Cells}

It has been reported that there are spontaneous glutamatergic synaptic currents in Purkinje cells (Kawa, 2002). To determine the possible role played by these currents in the response of Purkinje cells to ethanol, the effect of ethanol on bicuculline insensitive spontaneous currents was observed.

Spontaneous currents (in the absence of TTX) in Purkinje cells were recorded under wholecell voltage clamp. Because of the symmetric chloride concentration, both $\mathrm{Cl}^{-}$inhibitory and cation excitatory currents appear as inward currents. Application of $50 \mu \mathrm{M}$ bicuculline for 4 minutes reduced the frequency of spontaneous currents by $99.6 \pm 0.3 \%$ from a control value of $6.06 \pm 0.78$ to $0.02 \pm 0.01 \mathrm{~Hz}$ (paired $t$-test $p<0.01, n=18$ ). Bicuculline completely eliminated spontaneous inward currents in 16 of 18 cells (Fig. 2A) and reduced the frequency of spontaneous currents by 99 and $94 \%$ in the 2 remaining cells (Fig. 2B). The residual currents were blocked by application of CNQX and AP-5, suggesting that they were glutamatergic (Fig. 2C). Thus, the glutamatergic input to the Purkinje neurons under these recording conditions was negligible.

\section{Effect of Ethanol and GABA on Spontaneous Action Potentials}

The lack of effect of ethanol on mIPSC decay time may have been due to the experimental conditions used in the patch-clamp recording. To examine this possibility, we applied GABA directly to cerebellar Purkinje neurons in the presence and absence of ethanol and measured the effect on firing rate using extracellular recording. While GABA $(30 \mu \mathrm{M})$ reduced the action potential rate by approximately $20 \%$ (see Fig. 3A), ethanol alone did not alter the overall firing rate and the effect of GABA was similar in the presence and absence of ethanol (Fig. 3A). However, there was a significant correlation between the effect of ethanol and GABA on rate such that neurons sensitive to the rate reducing action of GABA were also slowed by ethanol while neurons less sensitive to GABA were unaffected or accelerated by ethanol as shown in Fig. 3B.

\section{Effects of Ethanol on Spontaneous Action Potentials of Cerebellar Purkinje Neurons}

The increase in inhibitory GABA release by ethanol and the lack of excitatory glutamatergic input would predict a general decrease in Purkinje neuron activity following ethanol administration. To test this hypothesis, spontaneous action potentials were recorded from cerebellar Purkinje neurons in the presence and absence of ethanol in a cerebellar slice. Application of $50 \mathrm{mM}$ ethanol (the concentration causing the greatest increase in GABAergic mIPSCs) altered the firing rate of most neurons examined. Percent changes in firing rates were not normally distributed (Shapiro-Wilk's $W$-test, $p<0.05, n=19$ ), indicating that the data were not from 1 entity. Thus, the data were divided into 2 groups according to either an increase or 
a decrease in firing rates in the presence of ethanol compared with control values. Examples of both increases (A) and decreases (B) in rate following ethanol administration are shown in Fig. 4.

For the group in which ethanol significantly increased firing rates from a control value of 9.7 \pm 1.0 to $11.7 \pm 0.9 \mathrm{~Hz}(n=11)$ during ethanol administration, the percent enhancement of firing was $25.2 \pm 7.9 \%$ (Fig. 4D). Firing rates during the application of ethanol in the second group of neurons were significantly decreased from a control value of $13.0 \pm 1.6$ to $11.1 \pm 1.4 \mathrm{~Hz}$ $(n=7)$ during ethanol administration. As shown in Figure 4D, the percent inhibition of firing rate by ethanol in this group was $14.6 \pm 3.4 \%$.

\section{Effect of Ethanol on Action Potential Pattern}

Application of $50 \mathrm{mM}$ ethanol to cerebellar Purkinje neurons produced a change in the pattern and rate of activity that began within seconds of the initial ethanol application and washed out within a few seconds of ethanol removal (see Figs. 4A and 4B). Fifty millimolar ethanol either reduced burst rate and prolonged burst duration or increased burst rate and shortened burst duration Fig. 5. The correlation of percent change in burst rates and percent change in firing rates in the presence of ethanol was significant $(r=-0.76, p<0.05, n=14$; Fig. 5A). Similarly, the correlation of percent change in burst duration and percent change in firing rate was also significant $(r=0.87, p<0.05, n=14$; Fig. 5B). These correlations indicate that the enhancement of firing rate by ethanol is associated with an increase in burst duration and a decrease in burst rate.

Within-burst interspike intervals were not significantly affected by $50 \mathrm{mM}$ ethanol. The interspike interval was $58.9 \pm 5.7$ milliseconds for control neurons and $54.4 \pm 6.2$ milliseconds in the presence of ethanol (paired $t$-test, $p>0.05, n=19$ ). Additionally, there was no correlation between percent change for within-burst interspike interval and percent change in firing rate ( $r=0.07, p>0.05, n=18)$. Thus, these data indicate that the change in firing pattern by ethanol, but not a change in within-burst interspike interval, was associated with the change in overall firing rate of Purkinje neurons when ethanol was applied.

\section{Effect of Ethanol on Spontaneous Action Potentials in Purkinje Cells During the Blockade of Synaptic Transmission}

The mixed effects of ethanol on action potential rate were not consistent with the increased inhibition predicted from the increased mIPSC frequency observed after ethanol administration. To determine the effect of ethanol on cerebellar Purkinje neurons in the absence of inhibitory and excitatory synaptic input, $100 \mu \mathrm{M}$ picrotoxin, $10 \mu \mathrm{M} \mathrm{CNQX}$, and $50 \mu \mathrm{M}$ AP-5 were included in the perfusion to block both $\mathrm{GABA}_{\mathrm{A}}$ receptors and glutamate receptors, respectively.

Under these conditions, the firing rate of Purkinje cells in the presence of $50 \mathrm{mM}$ ethanol (10.48 $\pm 1.47 \mathrm{~Hz})$ was significantly higher than under control conditions $(8.81 \pm 1.38 \mathrm{~Hz}$; paired $t$ test, $p<0.01, n=12$ ), resulting in an increase in firing rate by $23.6 \pm 4.3 \%$. This increased rate of Purkinje cell firing by ethanol under these conditions is represented in Fig. 6A. As was the case in the presence of external inputs to the Purkinje neuron, the correlation between percent change in firing rates and percent change in burst durations was significant (Fig. 6B; $r=0.70$, $p<0.05, n=10$ ), indicating that the potentiation of firing rates by ethanol was associated with prolongation of burst duration. Likewise, the negative correlation between percent change in firing rate and percent change in burst rate was significant (Fig. 6C; $r=-0.76, p<0.05, n=10$ ), indicating that the enhanced firing rate by ethanol is associated with a decreased burst rate. There was no correlation between percent change in within-burst interspike interval and percent change in firing rate $(r=-0.25, p>0.05, n=12)$. 


\section{DISCUSSION}

There is an inhibitory GABAergic input to cerebellar Purkinje neurons (Satake et al., 2004) and previous work has demonstrated that ethanol can enhance the release of GABA from presynaptic terminals (Ariwodola and Weiner, 2004; Crowder et al., 2002; Roberto et al., 2003; Ziskind-Conhaim et al., 2003). Because GABA release could be contributing to the inhibitory action of ethanol on firing rate for some, but not all, neurons (Freund et al., 1993; Yang et al., 2000), we examined the action of ethanol on GABA release on this cell type. Ethanol produced a concentration-dependent increase in the frequency of bicuculline-sensitive mIPSCs. These data indicate that the ethanol was increasing the presynaptic release of GABA. Ethanol had no effect on the amplitude or decay time of the mIPSCs, indicating that the sensitivity of the postsynaptic receptor to GABA was not changed. This is consistent with the majority of recent reports (see reviews by Breese et al., 2006; Criswell and Breese, 2005; and Siggins et al., 2005). However, Sanna et al. (2004) reported increased decay time as well as amplitude of mIPSCs from hippocampal neurons following ethanol. Altered intracellular $\mathrm{Cl}^{-}$ levels or other variables altered following dialysis of intracellular contents by the recording pipettes could have interfered with the effect of ethanol on postsynaptic $\mathrm{GABA}_{\mathrm{A}}$ receptors. For example, the $\mathrm{Cl}^{-}$transporters are likely overwhelmed. However, when these interfering variables were removed by the use of extracellular recording, there was still no consistent enhancement of the effect of GABA on rate by ethanol. While the present study did not find a direct action of ethanol on the postsynaptic $\mathrm{GABA}_{\mathrm{A}}$ receptor, other studies have suggested that ethanol might act at a specific site on the $\mathrm{GABA}_{\mathrm{A}}$ receptor to enhance the effectiveness of GABA (Ueno et al., 2000), but these actions may require higher concentrations of ethanol. For example Peoples and Weight (1999) indicated an $\mathrm{EC}_{50}$ concentration of $1.2 \mathrm{M}$ for a direct action of ethanol on $\mathrm{GABA}_{\mathrm{A}}$ receptors - a concentration well above the lethal dose and above the concentrations used in the present study. In previous work, we have been unable to see a direct effect of pharmacologically relevant concentrations of ethanol on GABA-gated currents from enzymatically isolated Purkinje neurons (Criswell et al., 2003). Other studies have indicated that indirect actions on the postsynaptic $\mathrm{GABA}_{\mathrm{A}}$ receptor, including phosphorylation of the receptor (Freund and Palmer, 1997; Harris et al., 1995; Weiner et al., 1997) and release of neuroactive steroids (Sanna et al., 2004) by ethanol could, increase the receptor sensitivity to GABA. The relatively brief application of ethanol in the present study might not have allowed sufficient time for occurrence of these processes. Under these recording conditions, glutamatergic input was completely absent in the vast majority of cells (16 of 18) and minimal in the remaining 2. Based upon these observations, an increased release of GABA with no change in glutamate release would predict an overall decrease in the firing rate of Purkinje neurons following ethanol.

To test the hypothesis that the increased GABA release would evoke a decrease in the firing rate of Purkinje neurons, the effect of the most effective concentration of ethanol to enhance GABA release was examined using extracellular recording. In agreement with results from earlier work (Bloom and Siggins, 1987; Franklin and Gruol, 1987; Rogers et al., 1980; Siggins et al., 1987), intoxicating concentrations of ethanol did not produce a net decrease in the firing rate of cerebellar Purkinje neurons. However, rather than forming a normal distribution around zero, ethanol caused an increase in firing rate for some neurons but a decrease in rate for others. These results suggest that ethanol has multiple actions on Purkinje neurons to produce this variable pattern of firing. For this reason, the effect of ethanol on the intrinsic pacemaker activity of Purkinje neurons was investigated to account for the variable effects of ethanol.

Previous work has indicated that the bursting pattern of cerebellar Purkinje neuron activity results from an intrinsic pacemaker activity (Edgerton and Reinhart, 2003). Because cerebellar Purkinje neurons are spontaneously active in the absence of synaptic inputs, we were able to examine the effect of ethanol on this intrinsic pacemaker function when the excitatory input 
was removed by the glutamate antagonists CNQX and AP-5 and the inhibitory input from GABA and glycine were eliminated by picrotoxin. Under these conditions, ethanol reliably increased the firing rate of the Purkinje neurons. When synaptic inputs are removed, cerebellar Purkinje neurons continue to fire in a bursting pattern. There was a strong correlation between overall change in rate and change in firing pattern following ethanol application such that increases in firing rate were associated with an increase in burst duration and a decrease in burst rate. There was no correlation between the within-burst interspike interval and change in rate. These data are consistent with an effect of ethanol that alters rate by a mechanism that controls the pattern of Purkinje neuronal activity but does not affect within-burst interspike interval. The present correlation between rate and firing pattern by ethanol further suggests that ethanol is having a direct action to alter intrinsic properties of the Purkinje neuron. The bursting pattern of activity in Purkinje neurons can be initiated by climbing fiber stimulation (Eccles et al., 1966) but occurs even in the absence of input from other neurons (Swensen and Bean, 2003, 2005; Womack and Khodakhah, 2004). The onset and offset of a burst is under the coordinated control of a number of voltage- and ligand-dependent $\mathrm{Na}^{+}, \mathrm{Ca}^{2+}$, and $\mathrm{K}^{+}$ channels (Swensen and Bean, 2005). While bursting occurs in acutely dissociated Purkinje neurons that lack their dendritic tree (Swensen and Bean, 2005), the mechanism may be somewhat different than bursting in a slice preparation, where termination of a burst appears to depend on dendritic calcium spikes (Womack and Khodakhah, 2004). The effects of ethanol on any one of these ion channels could alter burst characteristics.

The correlation between the sensitivity of cerebellar Purkinje neurons to GABA inhibition of rate and the effect of ethanol on rate would be consistent with varying strengths of the intrinsic drive between neurons such that it is more difficult to perturb the rate and pattern of activity of some neurons than of others by either GABA or ethanol. However, there are other possible mechanisms for the correlation between the effects of ethanol and GABA on rate. For example, neurons less sensitive to the inhibitory action of GABA would be less sensitive to the effect of increased GABA release by ethanol. The present methods do not allow a test of these alternatives.

An important question raised by these data is how an interaction of 2 variables with a normal distribution of either excitatory or inhibitory effects can result in an effect on neuronal activity that is not normally distributed. The most parsimonious explanation is that the excitatory effect of ethanol on the intrinsic pacemaker activity of the Purkinje neuron and the inhibitory effect of increased GABA release by ethanol are moderated by a homeostatic mechanism. Only a net excitation or a net inhibition sufficient to overcome homeostatic control will produce a change in activity of the Purkinje neuron. A second mechanism to produce a change in rate that is not normally distributed is a nonlinear interaction between the excitatory and inhibitory mechanisms. Either of these possibilities could explain the present results but they do not represent the only possible mechanisms.

Taken together, these data are consistent with 2 conflicting actions of ethanol on the cerebellar Purkinje neuron. An increase in inhibition due to a presynaptic action of ethanol to increase GABA release and a postsynaptic action of ethanol to increase the intrinsic excitatory drive of the Purkinje neuron. Interplay of these 2 actions may underlie a part of the complex effect of ethanol on the rate of firing of cerebellar Purkinje neurons.

\section{Acknowledgments}

Supported by AA11605 and AA1655. 


\section{REFERENCES}

Ariwodola OJ, Weiner JL. Ethanol potentiation of GABAergic synaptic transmission may be selflimiting: role of presynaptic GABA(B) receptors. J Neurosci 2004;24:10679-10686. [PubMed: 15564584]

Bloom FE, Siggins GR. Electrophysiological action of ethanol at the cellular level. Alcohol 1987;4:331337. [PubMed: 3304331]

Breese GR, Criswell HE, Carta M, Dodson P, Hanchar HJ, Khisti RT, Mameli M, Ming Z, Olsen RW, Otis TS, Parsons LH, Penland SN, Roberto M, Siggins GR, Valenzuela CF, Wallner M. Basis of the gabamimetic profile of ethanol. Alcohol Clin Exp Res 2006;30:731-744. [PubMed: 16573592]

Crews FT, Morrow L, Criswell HE, Breese GR. Ethanol effects on ion channels. Int Rev Neurobiol 1996;39:284-342.

Criswell HE, Breese GR. A conceptualization of integrated actions of ethanol contributing to its GABAmimetic profile: a commentary. Neuropsychopharmacology 2005;30:1407-1425. [PubMed: 15856077]

Criswell HE, Ming Z, Griffith BL, Breese GR. Comparison of effect of ethanol on $N$-methyl-D-aspartateand GABA-gated currents from acutely dissociated neurons: absence of regional differences in sensitivity to ethanol. J Pharmacol Exp Ther 2003;304:192-199. [PubMed: 12490591]

Crowder TL, Ariwodola OJ, Weiner JL. Ethanol antagonizes kainate receptor-mediated inhibition of evoked GABA(A) inhibitory postsynaptic currents in the rat hippocampal CA1 region. J Pharmacol Exp Ther 2002;303:937-944. [PubMed: 12438512]

Eccles JC, Llinas R, Sasaki K. The excitatory synaptic action of climbing fibres on the purinje cells of the cerebellum. J Physiol 1966;182:268-296. [PubMed: 5944665]

Edgerton JR, Reinhart PH. Distinct contributions of small and large conductance $\mathrm{Ca}^{2+}$-activated $\mathrm{K}^{+}$ channels to rat Purkinje neuron function. J Physiol 2003;548:53-69. [PubMed: 12576503]

Franklin CL, Gruol DL. Acute ethanol alters the firing pattern and glutamate response of cerebellar Purkinje neurons in culture. Brain Res 1987;416:205-218. [PubMed: 2887251]

Freund RK, Palmer MR. Beta adrenergic sensitization of gamma-aminobutyric acid receptors to ethanol involves a cyclic AMP/protein kinase A second-messenger mechanism. J Pharmacol Exp Ther 1997;280:1192-1200. [PubMed: 9067303]

Freund RK, van Horne CG, Harlan T, Palmer MR. Electrophysiological interactions of ethanol with gabaergic mechanisms in the rat cerebellum in vivo. Alcohol Clin Exp Res 1993;17:321-328. [PubMed: 8387727]

Givens BS, Breese GR. Electrophysiological evidence that ethanol alters function of medial septal area without affecting lateral septal function. J Pharmacol Exp Ther 1990a;253:95-103. [PubMed: 2329526]

Harris BD, Moody EJ, Gu ZQ, Skolnick P. Contribution of “diazepam-insensitive” GABAA receptors to the alcohol antagonist properties of Ro 15-4513 and related imidazobenzodiazepines. Pharmacol Biochem Behav 1995;52:113-118. [PubMed: 7501652]

Kawa K. Acute synaptic modulation by nicotinic agonists in developing cerebellar Purkinje cells of the rat. J Physiol 2002;538:87-102. [PubMed: 11773319]

Peoples RW, Weight FF. Differential alcohol modulation of GABA(A) and NMDA receptors. Neuroreport 1999;10:97-101. [PubMed: 10094141]

Roberto M, Madamba SG, Moore SD, Tallent MK, Siggins GR. Ethanol increases GABAergic transmission at both pre- and postsynaptic sites in rat central amygdala neurons. Proc Natl Acad Sci U S A 2003;100:2053-2058. [PubMed: 12566570]

Rogers J, Siggins GR, Schulman JA, Bloom FE. Physiological correlates of ethanol intoxication tolerance, and dependence in rat cerebellar Purkinje cells. Brain Res 1980;196:183-198. [PubMed: 7190454]

Sanna E, Talani G, Busonero F, Pisu MG, Purdy RH, Serra M, Biggio G. Brain steroidogenesis mediates ethanol modulation of GABAA receptor activity in rat hippocampus. J Neurosci 2004;24:6521-6530. [PubMed: 15269263] 
Satake S, Saitow F, Rusakov D, Konishi S. AMPA receptor-mediated presynaptic inhibition at cerebellar GABAergic synapses: a characterization of molecular mechanisms. Eur J Neurosci 2004;19:24642474. [PubMed: 15128400]

Siggins GR, Bloom FE, French ED, Madamba SG, Mancillas J, Pittman QJ, Rogers J. Electrophysiology of ethanol on central neurons. Ann N Y Acad Sci 1987;492:350-366. [PubMed: 3474932]

Siggins GR, Roberto M, Nie Z. The tipsy terminal: presynaptic effects of ethanol. Pharmacol Ther 2005;107:80-98. [PubMed: 15963352]

Swensen AM, Bean BP. Ionic mechanisms of burst firing in dissociated Purkinje neurons. J Neurosci 2003;23:9650-9663. [PubMed: 14573545]

Swensen AM, Bean BP. Robustness of burst firing in dissociated Purkinje neurons with acute or longterm reductions in sodium conductance. J Neurosci 2005;25:3509-3520. [PubMed: 15814781]

Ueno S, Lin A, Nikolaeva N, Trudell JR, Mihic SJ, Harris RA, Harrison NL. Tryptophan scanning mutagenesis in TM2 of the GABA(A) receptor alpha subunit: effects on channel gating and regulation by ethanol. Br J Pharmacol 2000;131:296-302. [PubMed: 10991923]

Urrutia A, Gruol DL. Acute alcohol alters the excitability of cerebellar Purkinje neurons and hippocampal neurons in culture. Brain Res 1992;569:26-37. [PubMed: 1611478]

Weiner JL, Valenzuela CF, Watson PL, Frazier CJ, Dumwiddie TV. Elevation of basal protein kinase C activity increases ethanol sensitivity of GABA(A) receptors in rat hippocampal CA1 pyramidal neurons. J Neurochem 1997;68:1949-1959. [PubMed: 9109521]

Womack MD, Khodakhah K. Dendritic control of spontaneous bursting in cerebellar Purkinje cells. J Neurosci 2004;24:3511-3521. [PubMed: 15071098]

Yang X, Criswell HE, Breese GR. Ethanol modulation of gamma-aminobutyric acid (GABA)-mediated inhibition of cerebellar Purkinje neurons: relationship to GABAb receptor input. Alcohol Clin Exp Res 2000;24:682-690. [PubMed: 10832910]

Ziskind-Conhaim L, Gao BX, Hinckley C. Ethanol dual modulatory actions on spontaneous postsynaptic currents in spinal motoneurons. J Neurophysiol 2003;89:806-813. [PubMed: 12574458] 


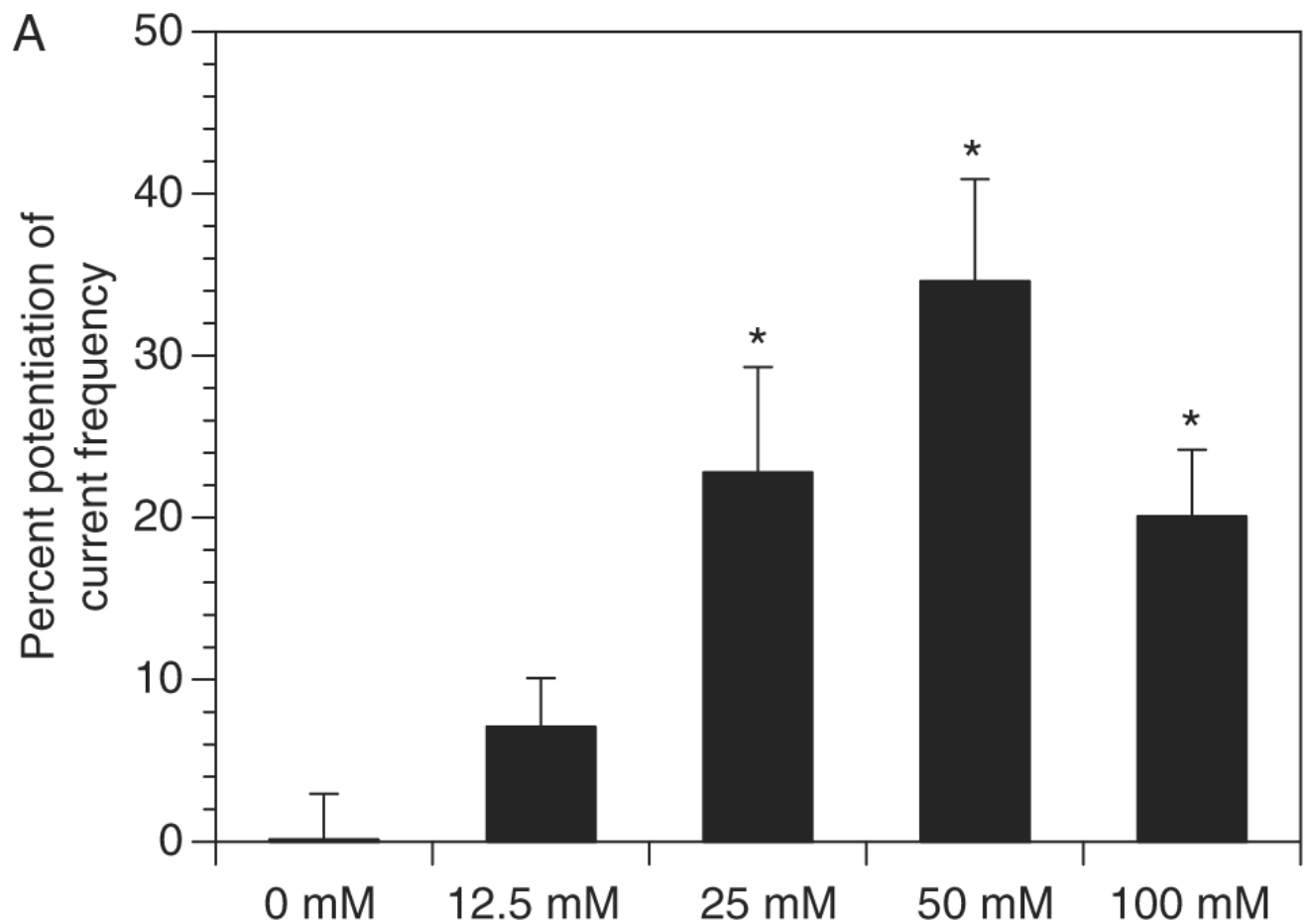

\section{B Control}

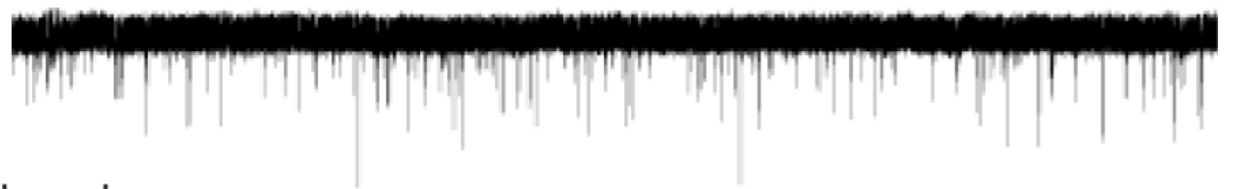

\section{Ethanol}

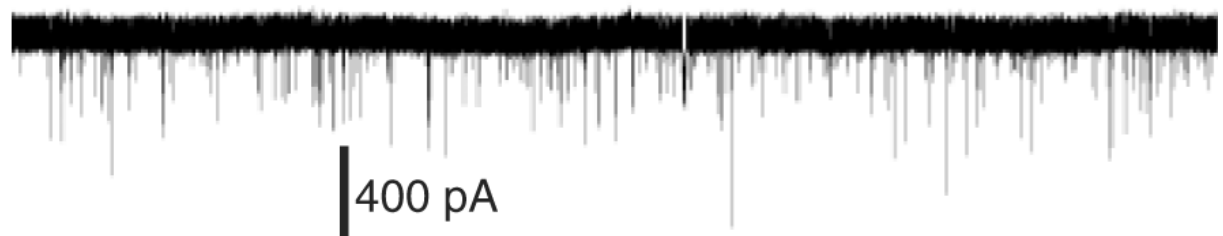

Wash out $5 \mathrm{sec}$.

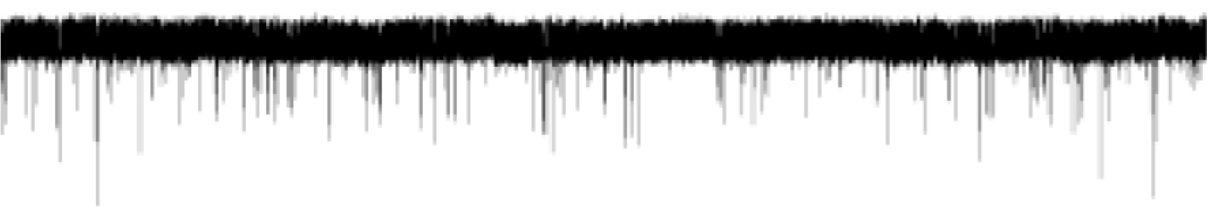

Fig. 1.

Bath administration of ethanol increased the frequency of miniature inhibitory postsynaptic currents (mIPSCs) in a concentration-related fashion. Each bar represents the mean of from 9 to 12 neurons (A). A representative recording of mIPSCs in the presence (ethanol) and absence (control and washout) of $50 \mathrm{mM}$ ethanol is shown in (B). 


\section{A Control}
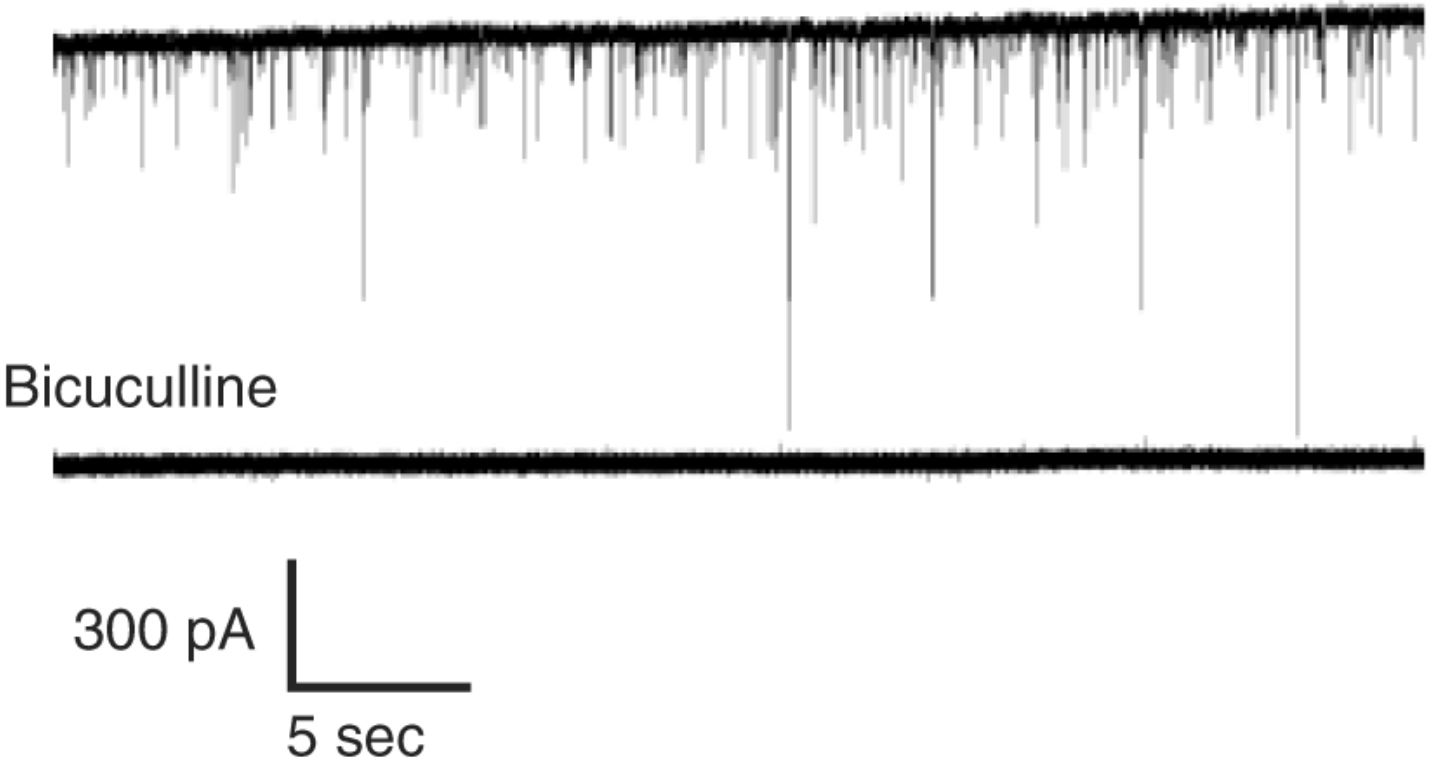

\section{B Control}

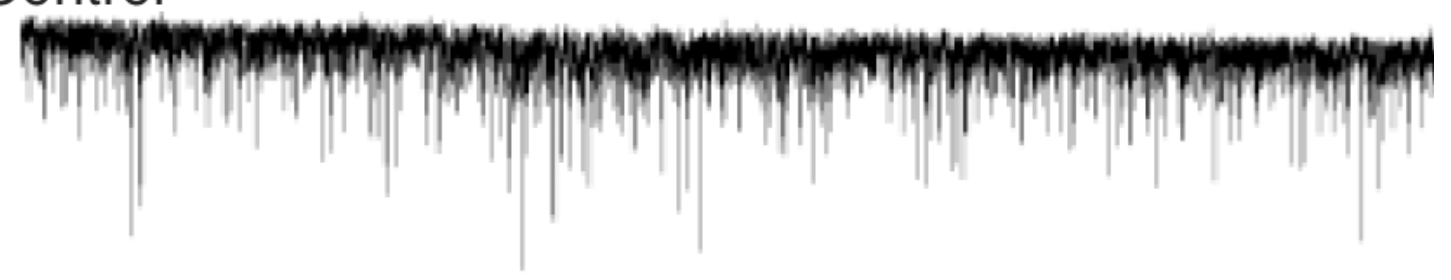

\section{Bicuculline}

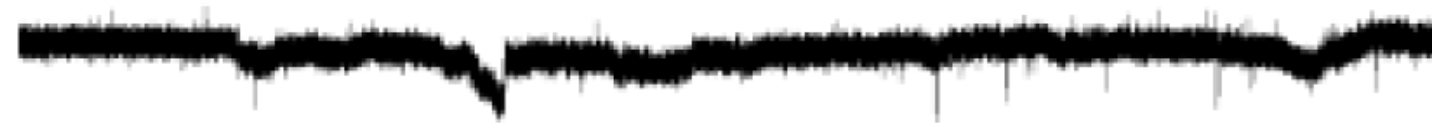

\section{Bicuculline+ CNQX + AP-5}

Fig. 2.

Bicuculline $(50 \mu \mathrm{M})$ completely abolished spontaneous currents in 16 of 18 cells as shown by a representative example from a neuron (A). In 2 cells, a few spontaneous currents remained after bicuculline administration as shown in $(\mathbf{B})$. Blockade of the remaining currents from the same neuron presented in (B) after coapplication of bicuculline; 6-cyano-7nitroquinoxaline-2,3-dione (CNQX) and AP-5 are shown in $(\mathbf{C})$. 

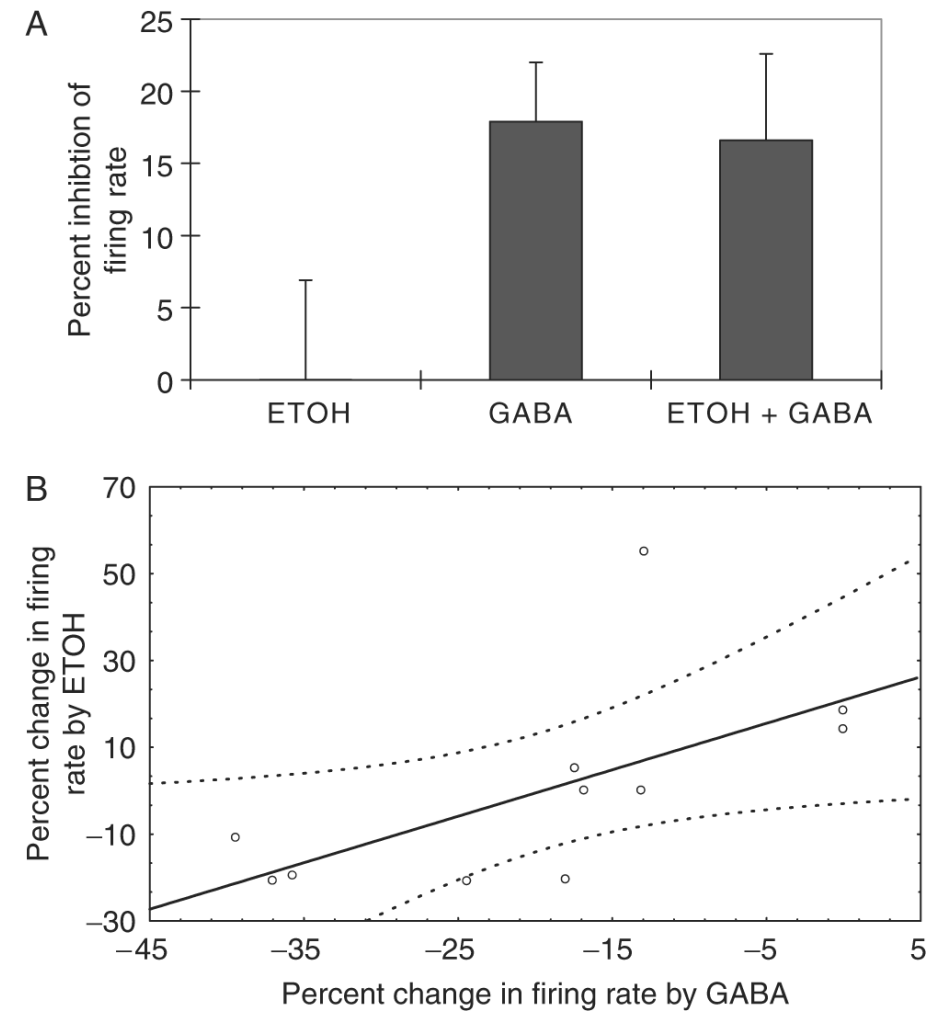

Fig. 3.

Mean percent change in rate during an extracellular recording from cerebellar Purkinje neurons following direct application of $50 \mathrm{mM}$ ethanol (ETOH), $30 \mu \mathrm{M} \gamma$-aminobutyric acid (GABA), or the combination of $50 \mathrm{mM}$ ethanol and $30 \mu \mathrm{M}$ GABA (ETOH+GABA) is shown in (A). Ethanol had no net effect alone and did not alter the inhibitory effect of the GABA when coapplied. However, when ethanol and GABA were applied separately to the same neuron, there was a significant correlation such that increased inhibition by ethanol was associated with an increase in inhibition by GABA $(\mathbf{B})$. The solid line represents the regression line, while the dashed lines represent the $95 \%$ confidence intervals for the regression. 
A

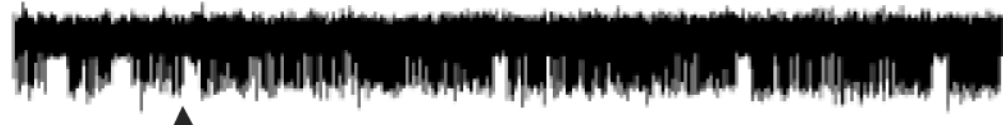

4

Ethanol

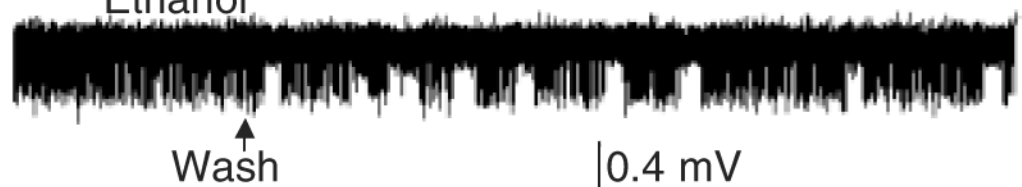

$5 \mathrm{sec}$

$\mathrm{B}$

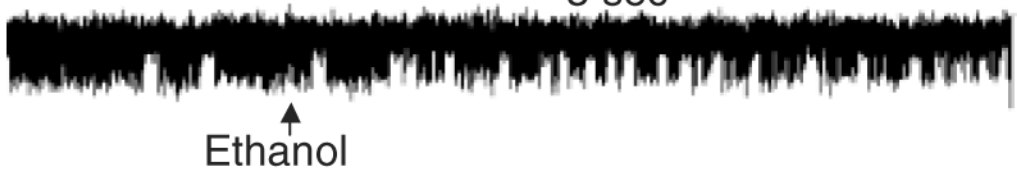

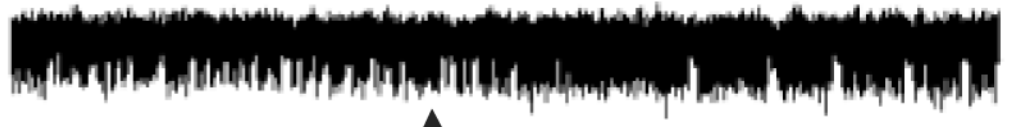

Wash b

C
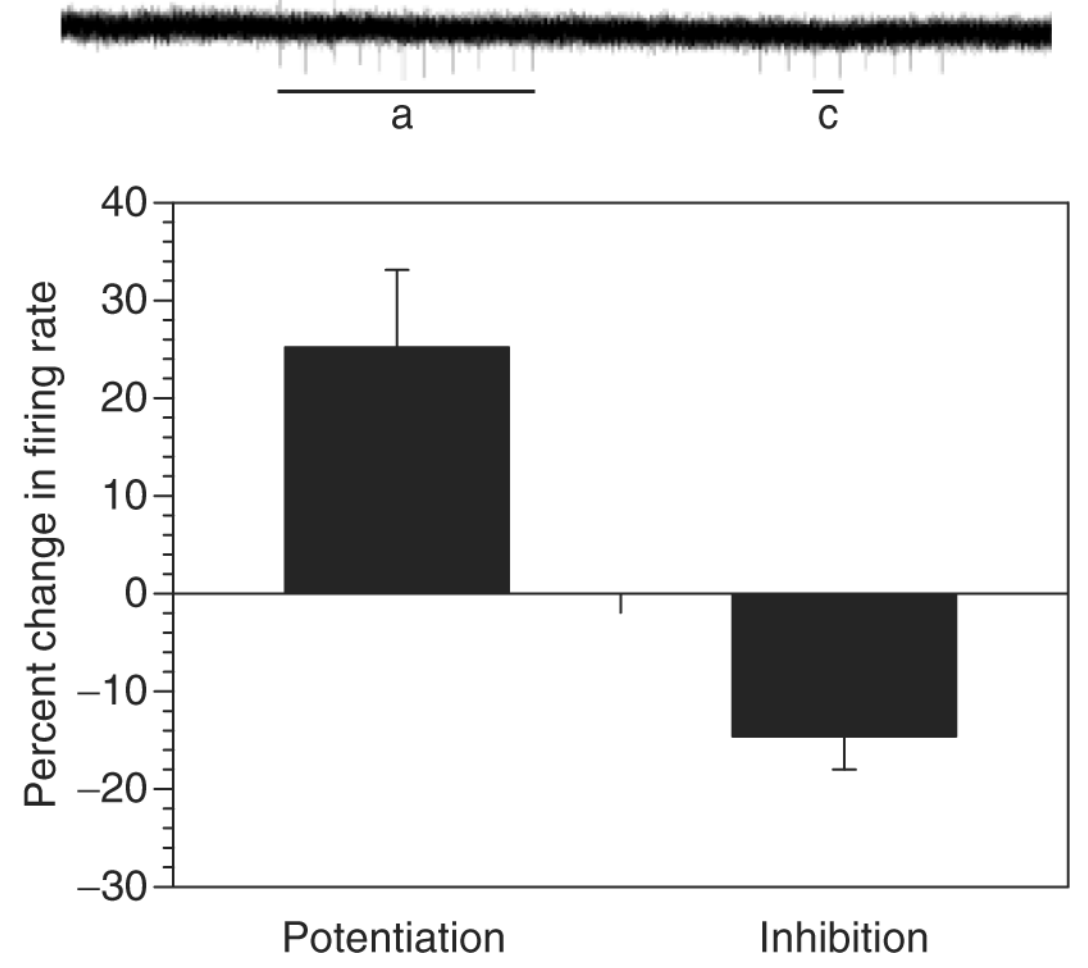

Fig. 4.

Representative extracellular recordings showing increases $(\mathbf{A})$ and decreases $(\mathbf{B})$ in firing rate following ethanol administration. Ethanol $(50 \mathrm{mM})$ was applied at the arrow. Note the prolonged burst duration associated with increased rate $(\mathbf{A})$ and the decreased burst duration associated with decreased rate $(\mathbf{B})$. The changes in firing pattern and rate occurred within a few seconds of the ethanol application (ethanol) and returned to baseline levels within a few seconds of return to the control solution (wash). An example of the patterned activity from a cerebellar Purkinje neuron is shown in $(\mathbf{C})$ to illustrate definitions of the recorded parameters. Burst duration is the time represented by the bar labeled (a). Interburst interval is the time represented by the bar labeled (b). Burst rate is $1 /$ interburst interval (b). Interspike interval 
within bursts is represented by the bar labeled (c). Mean ( \pm SEM) changes in firing rate recorded for 1 minute, beginning from 3 to 5 minutes after solution change, are shown in (D) for cells where firing rate increased or decreased. 

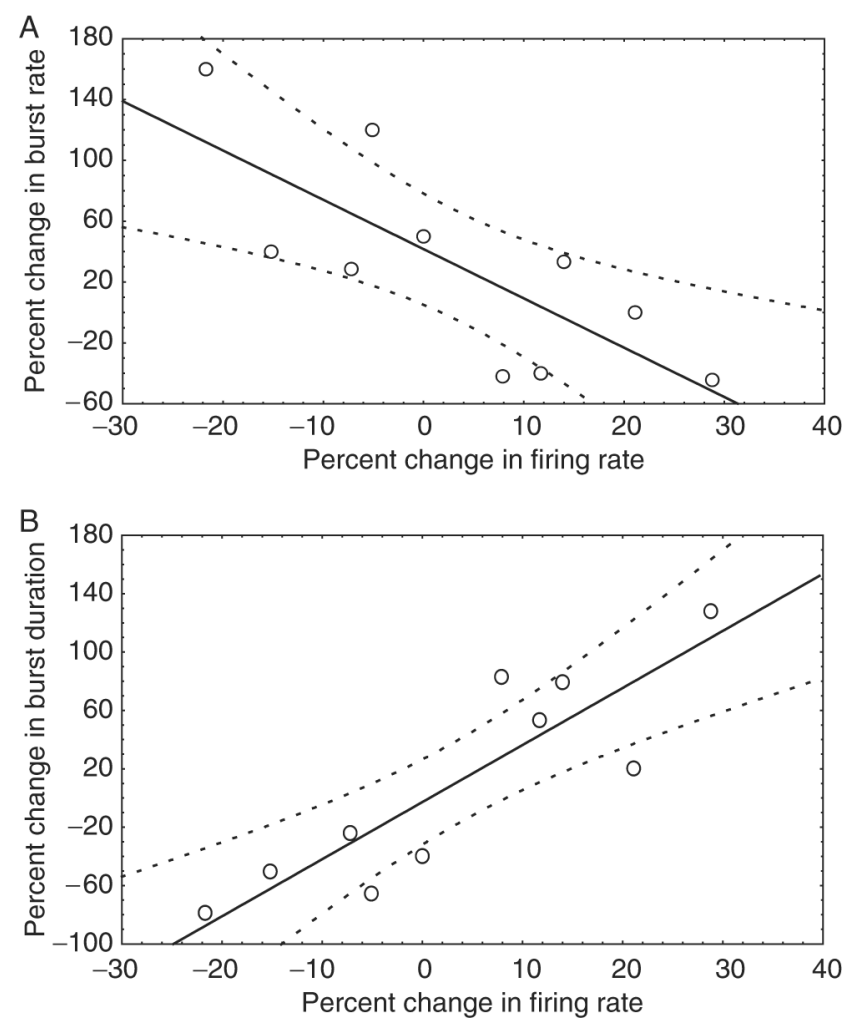

Fig. 5.

There was a negative correlation between percent change in firing rate and burst rate, such that burst rate decreased as overall firing rate increased $(\mathbf{A})$. There was a positive correlation between percent change in firing rate and burst duration such that burst duration increased as overall firing rate increased $(\mathbf{B})$. The solid line represents the regression line, while the dashed lines represent the $95 \%$ confidence intervals for the regression. 



Fig. 6.

A representative example of extracellular recording from a neuron showing increased firing rate following $50 \mathrm{mM}$ ethanol application is shown in (A). Note the prolonged burst duration in this example. The correlation between overall change in firing rate and change in burst duration $(\mathbf{B})$ and burst rate $(\mathbf{C})$ is similar to that of neurons with intact excitatory and inhibitory inputs (Fig. 5). The solid line represents the regression line, while the dashed lines represent the $95 \%$ confidence intervals for the regression. 
